\title{
A comparison of semi-quantitative methods suitable for establishing volatile profiles
}

\author{
Victoria Ruiz-Hernández ${ }^{1,2}$, María José Roca ${ }^{3}$, Marcos Egea-Cortines ${ }^{1,2}$ and Julia Weiss ${ }^{1,2^{*}}$ (0)
}

\begin{abstract}
Background: Full scent profiles emitted by living tissues can be screened by using total ion chromatograms generated in full scan mode and gas chromatography-mass spectrometry technique using Headspace Sorptive Extraction. This allows the identification of specific compounds and their absolute quantification or relative abundance. Quantifications ideally should be based on calibration curves using standards for each compound. However, the unpredictable composition of Volatile Organic Compounds (VOCs) and lack of standards make this approach difficult. Researchers studying scent profiles therefore concentrate on identifying specific scent footprints i.e. relative abundance rather than absolute quantities. We compared several semi-quantitative methods: external calibration curves generated in the sampling system and by liquid addition of standards to stir bars, total integrated peak area per fresh weight (FW), normalized peak area per FW, semi-quantification based on internal standard abundance, semi-quantification based on the nearest $n$-alkane and percentage of emission. Furthermore, we explored the usage of nearest components and single calibrators for semi-quantifications.

Results: Any of the semi-quantification methods based on a standard produced similar or even identical results compared to quantification by a true-standard for a compound, except for the method based on standard addition. Each method beholds advantages and disadvantages regarding level of accuracy, experimental variability, acceptance and retrieved quantities.

Conclusions: Our data shows that, except for the method of standard addition to the biological sample, the rest of the semi-quantification methods studied give highly similar statistical results. Any of the methodologies presented here can therefore be considered as valid for scent profiling. Regarding relative proportions of VOCs, the generation of calibration curves for each compound analysed is not necessary.
\end{abstract}

Keywords: GC-MS, HSSE, Internal standard, Calibration curve, Quantification, Scent profile, Stir bars, Twisters, VOCs

\section{Background}

The emission of Volatile Organic Compounds (VOCs) is a biological feature of bacteria, fungi, plants and animals. They play a key role in interaction between individuals of the same and other species, genera and kingdoms [1-3]. The number of identified VOCs emitted in nature is constantly increasing as the analytical techniques improve

\footnotetext{
*Correspondence: julia.weiss@upct.es

${ }^{1}$ Instituto de Biotecnología Vegetal, Universidad Politécnica de Cartagena, Cartagena, Spain

Full list of author information is available at the end of the article
}

and biodiversity is scrutinized for its chemical diversity. Numerous ecological studies are focusing on VOC functions i.e. the mediation of plant defence by volatile compounds in plant communities [4].

VOCs emission by plants can be very variable, especially in flowers where different compounds comprising a specific scent profile may be counted in dozens [5]. Bioactivity of VOCs emitted by flowers is diverse and not fully understood yet. While some of these compounds are known to have an effect over pollinator attraction, others may act as repellents $[6,7]$. 
In order to identify as many compounds as possible in a given sample, researchers use HSSE, and GC-MS using TICs when screening scent profiles. A scent profile is understood as the combination and proportion of VOCs which is conserved for a certain set of samples and reflect a combination of the genotype and environmental conditions.

The composition of floral scent profiles is robust for a given species [8]. Most scientists distinguish major and minor VOCs, where major compounds are emitted in higher quantities and can be interpreted as the characteristic footprint of a species. Minor compounds contribute to the fine tuning of the ultimate bouquet. The VOCs emitted by a plant organ changes depending on the time of the day, physiological stage and biotic and abiotic external factors [9-11].

An appropriate quantification of compounds ideally requires the use of a specific standard for each compound present in the sample $[12,13]$. Considering that plant VOCs may be present in dozens, their quantifications based on the inclusion of standards for each VOC increases the economic costs considerably [14]. An additional problem is that pure standards may not be available for most compounds $[15,16]$. Furthermore, while some scent profiles are composed of VOCs emitted constitutively, other compounds are emitted only under certain circumstances, and the appropriate standards are therefore not known a priori [17]. Finally, there are VOCs that are known for having several isomers with differing Chemical Abstract Service number and therefore a potential standard. As a result, performing appropriate quantifications of VOCs emitted by plants is not straightforward.

Due to the high costs and lack of standards for every chemical compound, other methods that allow semiquantification of compounds can be used. The most common method is the usage of single internal standards for extrapolating quantities [10, 18-20]. Moreover, several internal standards can be used for semi-quantifying nearest or similar components within the chromatogram [15, 21]. However, the use of internal standards has some drawbacks related to the response of VOCs during the chromatographic analysis, such as differential binding to the adsorption fiber [22, 23].

Here we compared external calibrators obtained by adding standards to the sampling system, external calibrators by liquid addition to stir bars, calculation of integrated peak area.gFW ${ }^{-1}$, calculation of normalized peak area.gFW ${ }^{-1}$, semi-quantification based on internal standard, semi-quantification based on external calibrator area using the NearestRT $n$-alkane. Our results indicate that except for the semi-quantification by standard addition to the biological sample, the rest of the methods studied give highly similar statistical results. Furthermore, results indicate that the use of a standard for each VOC analysed in the context of scent profiles studies can be omitted.

\section{Methods \\ Plant material and VOCs collection}

We used completely developed 3-4 days old flowers of the Antirrhinum majus inbred line $165 \mathrm{E}[8,24]$ in order to generate the raw data which were then used to compare semi-quantification methods. Additionally, a flower scent profile was generated for Petunia $x$ hybrida line Mitchell. The sampling system consisted in flowers placed inside a beaker with $4 \mathrm{ml}$ of $5 \%$ sucrose in distilled water, supported by a glass slide, and a stir bar was attached to the border of the beaker with a stainless-steel paperclip. The beaker was then placed in a 2-1 desiccator (Fig. 1).

Flowers for CG-MS analysis were kept under conditions of $12 \mathrm{~h}$ light and $12 \mathrm{~h}$ dark at $23{ }^{\circ} \mathrm{C}$ and $18{ }^{\circ} \mathrm{C}$, respectively, in a growth chamber (Sanyo MRL 350). In case of $A$. majus, stir bars sampled the floral volatiles of 3 flowers in 3 different desiccators during $12 \mathrm{~h}$ of light or $12 \mathrm{~h}$ of dark periods. In case of Petunia $x$ hybrida, stir bars sampled floral volatiles for 4 or $24 \mathrm{~h}$, sampling times applied in circadian rhythm studies [25]. The VOC profile of $A$. majus, is based on compounds which appeared unanimously in the day and night replicas (Table 1). Contaminants were identified and omitted in subsequent analyses.

We used $10 \mathrm{~mm}$ long Twisters ${ }^{\mathrm{TM}}$ (Gerstel, Mülheim an der Ruhr, Germany) (stir bars), covered with a $0.5 \mathrm{~mm}$ film of polydimethylsiloxane (PDMS). We also tested dual-phase stir bars (ethylene glycol and silicone) (Gerstel, Mülheim an der Ruhr, Germany). Both types of stir

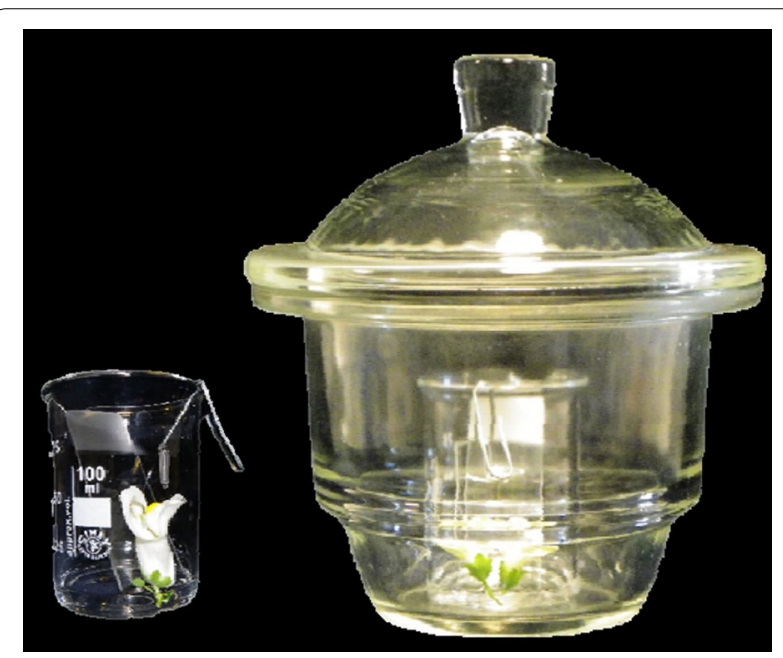

Fig. 1 Sampling system for VOCs in HSSE 
Table 1 Chromatographic parameters for A. majus VOCs analysed in column HP5 MSVi

\begin{tabular}{|c|c|c|c|c|c|}
\hline Retention time & Compound & CAS & LRI & LRI bibliography & Reference \\
\hline 2.23 & Methyl 2-methylbutanoate & $868-57-5$ & 805 & 774 & {$[26]$} \\
\hline 5.58 & $\beta$-myrcene & $123-35-3$ & 996 & 991 & {$[27]$} \\
\hline 6.62 & Ocimene & $6874-10-8$ & 1044 & 1038 & {$[28]$} \\
\hline 7.19 & Acetophenone & $98-86-2$ & 1071 & 1065 & {$[27]$} \\
\hline 7.77 & Methyl benzoate & $93-58-3$ & 1099 & 1091 & {$[27]$} \\
\hline 7.96 & Nonanal & $124-19-6$ & 1107 & 1104 & {$[29]$} \\
\hline 9.03 & Acetophenone, 2'-hydroxy & $118-93-4$ & 1167 & 1160 & {$[26]$} \\
\hline
\end{tabular}

bars were conditioned for adsorption according to manufacturer indications.

Compounds adsorbed by the stir bars were analysed by GC-MS in a gas chromatograph HP-6890N coupled to a 5975 mass spectrometer (Agilent Technologies, Palo Alto, USA) combined with a TDU and cooling injector system (CIS4) (Gerstel, Mülheim an der Ruhr, Germany).

Desorption was carried out by heating from an initial temperature of $40^{\circ}$ to $250{ }^{\circ} \mathrm{C}$ at $100{ }^{\circ} \mathrm{C} \mathrm{min}{ }^{-1}$ with $5 \mathrm{~min}$ hold time on splitless mode. Desorbed compounds were captured in a cool trap at $-100{ }^{\circ} \mathrm{C}$. This process was automated by using a multipurpose sampler MPS2XL (Gerstel, Mülheim an der Ruhr, Germany).

Chromatographic separation was done in a HP5MSUI column (Agilent Technologies, Palo Alto, USA) with helium as gas carrier in constant pressure mode and split ratio $1: 50$. Initial temperature was $50{ }^{\circ} \mathrm{C}$, increasing at a ratio of $5{ }^{\circ} \mathrm{C} \mathrm{min}^{-1}$ until $70{ }^{\circ} \mathrm{C}$ held $1 \mathrm{~min}$. In the next step, temperature was increased until $240{ }^{\circ} \mathrm{C}$ at $10{ }^{\circ} \mathrm{C} \mathrm{min}{ }^{-1}$ held for $15 \mathrm{~min}$.

The mass spectrometer operated at $70 \mathrm{eV}$ ionization voltage. Source and quadrupole temperatures were 230 and $150{ }^{\circ} \mathrm{C}$, respectively. Mass range was 30.0 to 450.0 uma at $4 \mathrm{scan} / \mathrm{s}$. MSD transfer line was maintained at $280^{\circ} \mathrm{C}$.

We used ChemStation software (version E.02.02 SP1, Agilent Technologies, Palo Alto, USA) to acquire chromatograms. Compounds were qualitatively identified by comparison with mass spectral database Willey10thNIST11b (Agilent Technologies, Wilmington, USA), considering match qualities above $90 \%$. We used ocimene, acetophenone, methyl benzoate and methyl cinnamate (Sigma-Aldrich, W353901, 42163, 18344 and 96410, respectively) as standards. Methanol was used as solvent for dilution of standards (Panreac, 361091). Linear retention indexes (LRI) were calculated as a parameter for identifying compounds by comparing with retention times (RT) of C8-C20 alkanes (Sigma Aldrich, 04070), analysed under the same chromatographic conditions (Table 1) [30].

\section{Semi-quantitative methods of VOCs analysis}

We analysed raw data using: (1) external calibrators obtained by adding standards to the sampling system, (2) external calibrators obtained by liquid addition to stir bars, (3) calculation of integrated peak area.gFW ${ }^{-1}$, (4) calculation of normalized peak area.gFW ${ }^{-1}$, (5) semiquantification based on internal standard, (6) semiquantification based on external calibrator area using the NearestRT $n$-alkane and (7) percentage calculation.

\section{Method 1. Calibration curves obtained by adding standards to the sampling system}

We used two different methods to apply standards to the sampling system, method $1 \mathrm{~A}$ generates calibration curves by standard addition, whereas method $1 \mathrm{~B}$ generates external calibration curves.

In the first case (method 1A), a mixture of standards (25, 50 and $100 \mathrm{mg} / \mathrm{L}$ ) including ocimene, acetophenone, methyl benzoate and methyl cinnamate was added directly to the sucrose solution together with four individual Antirrhinum flowers of the same plant, distributed in four desiccators. This experiment was duplicated.

In the second case (method 1B), standards with different concentrations of ocimene, acetophenone, methyl benzoate and methyl cinnamate were added directly to the sucrose solution without flower (Table 2). The concentration ranged from 11.25 to $900 \mathrm{mg} / \mathrm{L}$ (ocimene) and from 50 to $1000 \mathrm{mg} / \mathrm{L}$ (acetophenone, methyl benzoate and methyl cinnamante). A total of 6 standard mixtures with 3 replicas were applied to different sampling systems. Calibration curves were obtained by using Chemstation. We used the total integrated peak area of each compound for further semi-quantification and the calibrator approaches A) and B) as described below.

\section{Method 2. External calibration curves obtained by adding standards to stir bars}

The same aforementioned standards were used in order to obtain calibration curves by adding liquid aliquots directly to stir bars. The concentration of ocimene ranged 
Table 2 External calibration curves carried out in headspace and by liquid addition of standards to stir bars

\begin{tabular}{|c|c|c|c|c|c|}
\hline External calibration curve & Standard & Retention time & Calibration curve & $r^{2}$ & Unit \\
\hline \multirow[t]{5}{*}{ Standards to sampling system (1B) } & Ocimene (E) & 6.60 & $6.299 \cdot 10^{8} \times$ & 0.98 & \multirow[t]{5}{*}{ mg } \\
\hline & Ocimene (Z) & 6.80 & $1.196 \cdot 10^{9} \times$ & 0.98 & \\
\hline & Acetophenone & 7.20 & $5.247 \cdot 10^{8} \times$ & 0.96 & \\
\hline & Methyl benzoate & 7.77 & $1.345 \cdot 10^{9} \times$ & 0.96 & \\
\hline & Methyl cinnamate & 12.61 & $2.891 \cdot 10^{9} \times$ & 0.99 & \\
\hline \multirow[t]{5}{*}{ Standards to stir bars (2) } & Ocimene (E) & 6.54 & $3.424 \cdot 10^{6} \times-9.325 \cdot 10^{4}$ & 0.99 & \multirow[t]{5}{*}{$\mu \mathrm{g}$} \\
\hline & Ocimene (Z) & 6.81 & $8.318 \cdot 10^{6} x-1.397 \cdot 10^{5}$ & 0.99 & \\
\hline & Acetophenone & 7.18 & $1.052 \cdot 10^{7} \times-2.693 \cdot 10^{5}$ & 0.99 & \\
\hline & Methyl benzoate & 7.78 & $1.181 \cdot 10^{7} \times-1.009 \cdot 10^{5}$ & 0.99 & \\
\hline & Methyl cinnamate & 12.66 & $1.762 \cdot 10^{7} \times-5.245 \cdot 10^{5}$ & 1 & \\
\hline
\end{tabular}

from 25 to $500 \mathrm{mg} / \mathrm{L}$ while acetophenone, methyl benzoate and methyl cinnamate ranged from 50 to $500 \mathrm{mg} / \mathrm{L}$. A total of 5 standard mixtures with 3 replicas were applied to different stir bars in an injection volume of $0.5 \mu \mathrm{l}$. Calibration curves were obtained by using Chemstation (Table 2).

As in case of method $1 \mathrm{~B}$, we used the total integrated peak area of each compound for furthersemi-quantification, and the calibrator approaches (A) and (B) as described below:

(A) NearestRT: semi-quantifying those compounds lacking standards by using as calibration curve the nearest component among ocimene, methyl benzoate and acetophenone. In this case for instance, we have semi-quantified nonanal (RT $7.958 \mathrm{~min}$ ) with the methyl benzoate (RT 7.773) calibration curve.

(B) Single calibrator: using a single calibration curve (ocimene, methyl benzoate or acetophenone) for quantifying all the compounds on the scent profile of $A$. majus. For instance, using methyl benzoate calibration curve to semi-quantify the emission of each compound of interest: methyl 2-methylbutanoate, $\beta$-myrcene, ocimene, acetophenone, methyl benzoate, nonanal and acetophenone 2-hydroxy.

\section{Method 3. Calculation of peak area per fresh weight}

The relative abundance of compounds was expressed as the total integrated area of each compound divided by the FW of the sample.

\section{Method 4. Calculation of normalized peak area per fresh weight}

Normalization of peak areas of each compound was done by using 1-phenylethanol (RT 7.096, SigmaAldrich, P13800) as an internal standard by adding
$10 \mu \mathrm{L}(0.1 \%)$ to the sucrose solution during the flower scent analysis. The normalized peak areas of all compounds were calculated by dividing their total integrated peak area by the integrated peak area of the internal standard.

\section{Method 5. Semi-quantification based on a single internal standard peak}

Semi-quantification was done by extrapolating the area of $10 \mu \mathrm{L}(0.1 \%)$ of 1 -phenylethanol (added to each sample) to the integrated area of every compound in the profile.

\section{Method 6. Semi-quantification based on the NearestRT n-alkane}

We added $1 \mu$ of $n$-alkane standard solution C8-C20 (Sigma Aldrich, 04070) to a stir bar. The default concentration of each $n$-alkane in the solution was $40 \mathrm{mg} / \mathrm{L}$. Each $n$-alkane was used as an external calibrator of the NearestRT compound of interest (Table 3). Integrated areas of the NearestRT $n$-alkane were used for semiquantification by extrapolating the area of $40 \mathrm{mg} / \mathrm{L}$ of the nearest $n$-alkane to the integrated area of the compound of interest.

\section{Method 7. Percentage analysis}

In order to calculate the percentage of VOCs from raw data profiles, we selected 7 compounds emitted both during day and night by Antirrhinum flowers. The sum of emission of these 7 compounds was considered as $100 \%$.

\section{Statistics}

We performed statistical analysis on the raw data for every semi-quantification method described above. 
Table 3 Alkanes used for semi-quantifying compounds of interest

\begin{tabular}{llll}
\hline $\begin{array}{l}\text { RT } \\
\text { compound }\end{array}$ & Compound & $\begin{array}{l}\text { RT } \\
\text { alkane }\end{array}$ & $\begin{array}{l}\text { Alkane used } \\
\text { for semi- } \\
\text { quantification }\end{array}$ \\
\hline 2.23 & Methyl 2-methylbutanoate & 2.325 & Octane \\
5.58 & B-myrcene & 5.820 & Decane \\
6.62 & Ocimene & 5.820 & Decane \\
7.19 & Acetophenone & 7.954 & Undecane \\
7.77 & Methyl benzoate & 7.954 & Undecane \\
7.96 & Nonanal & 7.954 & Undecane \\
9.03 & Acetophenone, 2'-hydroxy & 9.797 & Dodecane \\
\hline
\end{tabular}

Raw data generated during the day were used to analyse proportional variations of each compound within the scent profile. Second, we retrieved the differences in the day vs. night emission of the compounds of interest. Levene's, one-way ANOVA and Tukey's tests were performed by using $\mathrm{R}$ (Rcmdr package).

\section{Results}

\section{Comparison of stir bars and sampling time in HSSE}

We tested two types of stir bars commercially available, the PDMS and dual-phase. Based on the adsorption characteristics, dual-phase should perform better than PDMS adapted to HSSE. However, we obtained a very high background noise by using the dual-phase stir bars (Fig. 2), that may completely cover true signals from biological tissues. Our results indicate that dual-phase stir bars are not suitable to sample complex matrices, such as flowers, due to the high noisy background introduced (Fig. 2). We therefore performed the rest of the measurements and experiments with PDMS bars.
Most plants emit their floral scent preferentially at certain times of the day. Plants emitting mostly during the day include rose, narcissus or Antirrhinum, while plants with preferential night emission include Petunia or Nicotiana [11, 31, 32]. As sampling frequency plays a role in the detection of circadian rhythms, we tested the effect of sampling time on VOC profiles analysed by HSSE. We sampled a Petunia flower for 4 and $24 \mathrm{~h}$. Figure 3 shows a chromatogram after $4 \mathrm{~h}$ of sampling compared to $24 \mathrm{~h}$ of sampling under identical conditions. Sampling periods did not seem to affect greatly the acquisition of major compound (Fig. 3a, b). However, the total number of compounds as well as abundances of VOCs were notably affected by sampling time (Fig. 3c, d). Minor VOCs such as benzyl acetate (CAS 140-11-4, RT 9.087, quality 97), benzyl 2-methylbutyrate (CAS 56423-40-6, RT 12.625, quality 97) and (Z)-isoeugenol (CAS 5912-86-7, RT 12.939 , quality 98 ) were detected only in samplings of $24 \mathrm{~h}$. Our results show that sampling time needs to be taken into account when characterising VOC profiles of plant species based on HSSE.

\section{Comparison of semi-quantification methods Method 1. Calibration curves obtained by adding standards to the sampling system}

The feasibility of using calibration curves in the headspace was tested using two approaches. In case of method $1 \mathrm{~A}$, we intended to quantify four compounds, ocimene, methyl benzoate, acetophenone and methyl cinnamate by adding mixtures of these standards together with the flower. We used flowers of the same plant for each concentration in order to obtain the corresponding calibration curves and eliminate the matrix effect (Fig. 4a-e). We expected a linear evolution of peak areas for each compound, but instead we observed high variation

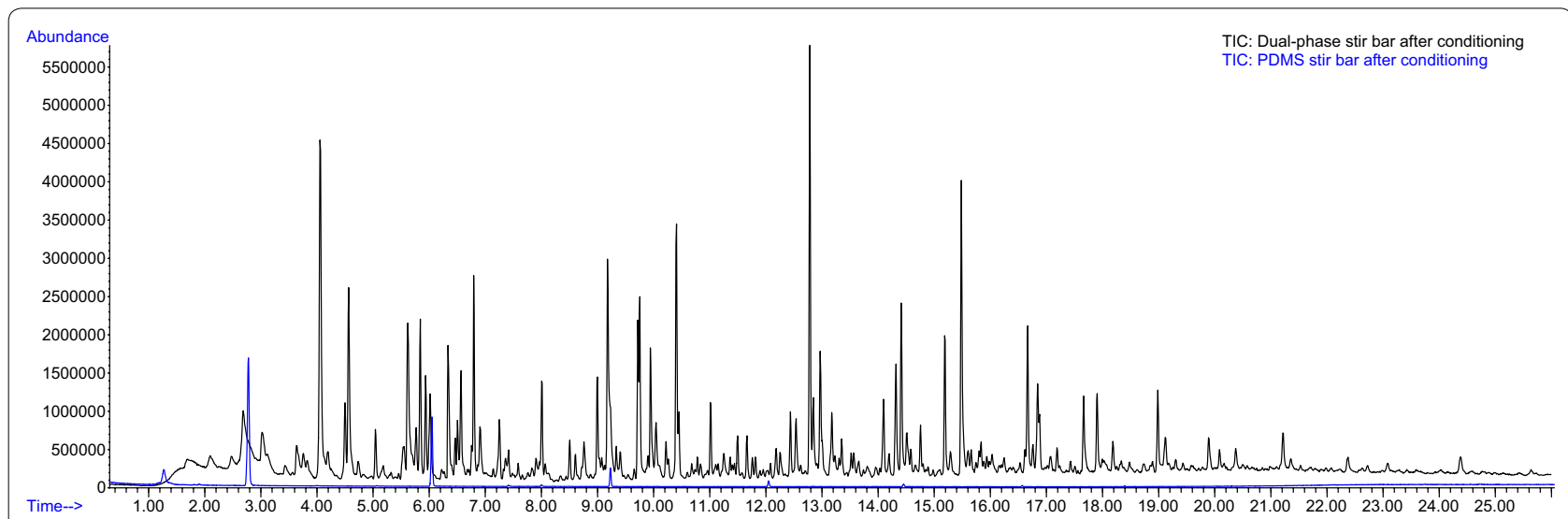

Fig. 2 Comparison of commercially available stir bars: blank chromatograms of dual-phase and PDMS stir bars after conditionings according to the indications of manufacturer 


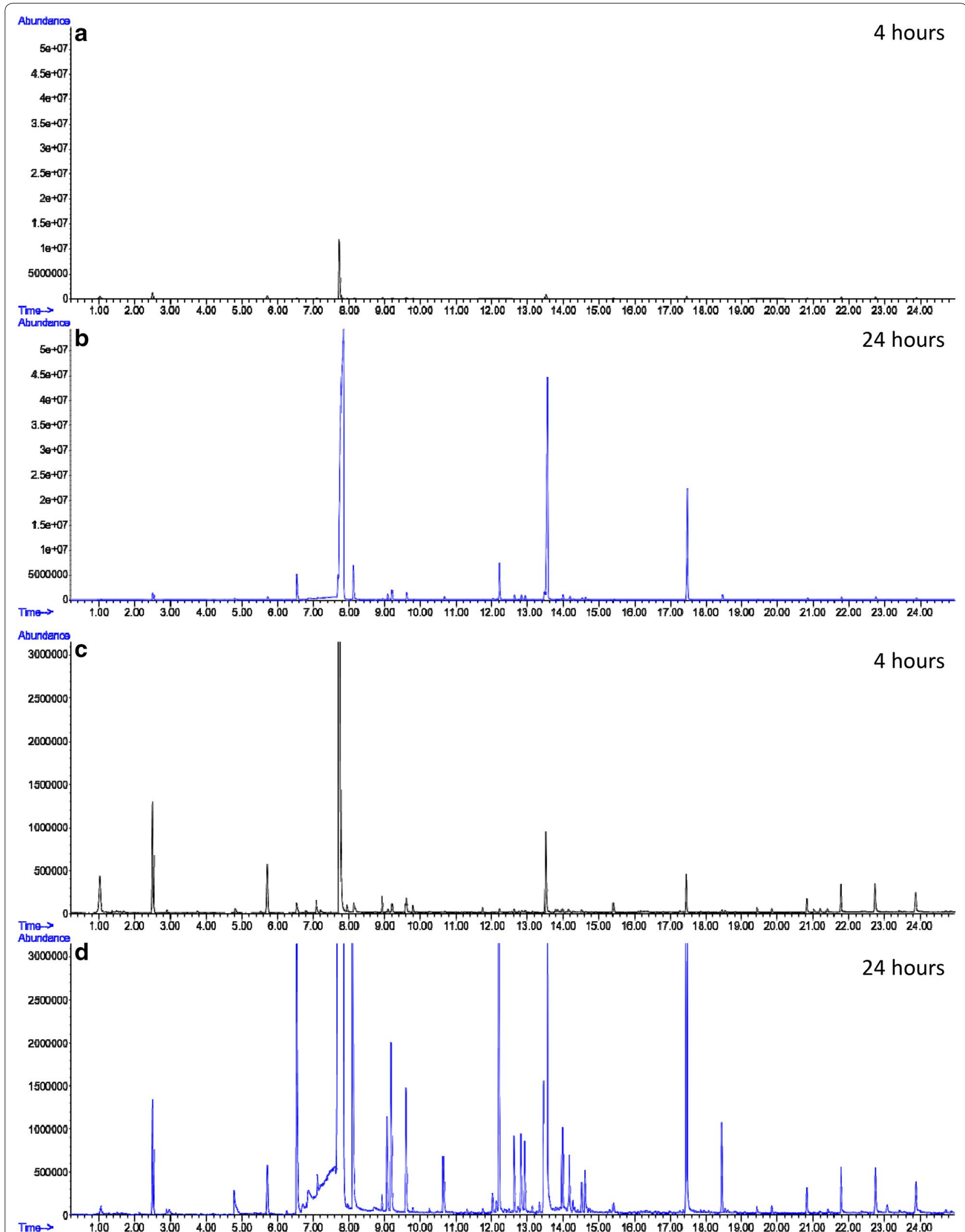

Fig. 3 Effect of sampling time on the identification of VOCs. Comparison of floral scent chromatograms of Petunia after $4 \mathrm{~h}(\mathbf{a}, \mathbf{c})$ and $24 \mathrm{~h}(\mathbf{b}, \mathbf{d})$ of sampling. $\mathbf{c}, \mathbf{d}$ are close ups of chromatograms $(\mathbf{a}, \mathbf{b})$. Scales of $\mathbf{a}, \mathbf{b}$, and $\mathbf{c}, \mathbf{d}$ are the same for comparison 


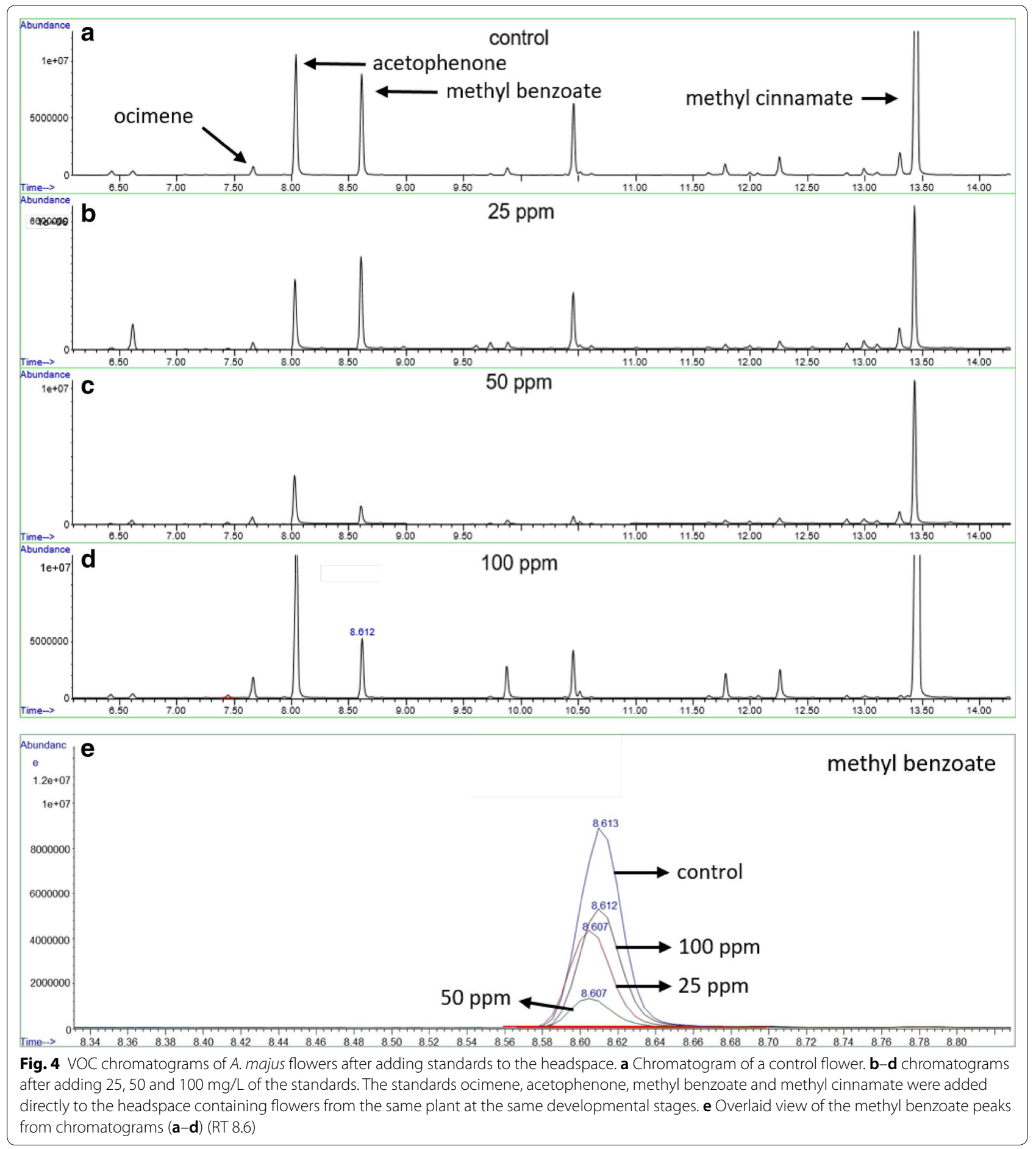

between flowers, indicating that this calibration procedure is not applicable based on the high natural variability among flowers of one plant. This problematic is illustrated in the chromatogram of a control flower that emits more methyl benzoate than those supplemented with standard solutions (Fig. 4e), indicating that this method does not allow an appropriate quantification.

In case of method 1B, we semi-quantified our raw data of $A$. majus VOCs with external calibration curves carried out by adding standards to the sampling system 
without flowers (Table 2) using the approaches NearestRT (semi-quantifying those compounds lacking standards by using the calibration curve of the nearest component) and single calibrator. Results show that quantities obtained by the NearestRT procedure or by a single calibrator ocimene or methyl benzoate (Fig. 5a, b, d) peaked at over $1000 \mu \mathrm{gFW}^{-1}$. In contrast, in case of acetophenone as single calibrator, quantities were over a $40 \%$ higher (Fig. 5c). Concerning differences in the scent profile during the light period, we found two patterns. While single calibrators (Fig. 5b-d) resulted in an identical statistical difference pattern with significant differences among acetophenone and ocimene (Tukey $p$ value 0.0017), acetophenone was not different from ocimene (Tukey $p$ value 1 ) in case of the NearestRT calibration
(Fig. 5a, Additional file 1: Tables S1, S2 and S3). Differences in VOCs between day and night using different calibrator approaches were identical with ANOVA $p$ value of $0.0057,0.024$ and 0.017 , respectively, for $\beta$-myrcene, ocimene and nonanal (Fig. 5, Additional file 1: Tables S4 and S5).

\section{Method 2. External calibration curves carried out by liquid addition to stir bars}

Following the same key principles applied to the prior way of semi-quantifying (NearestRT and single calibrator), we semi-quantified our raw data of A. majus VOCs emitted during the light and dark periods by using external calibration curves obtained by adding standards directly to stir bars (Table 2). We first analysed statistical a

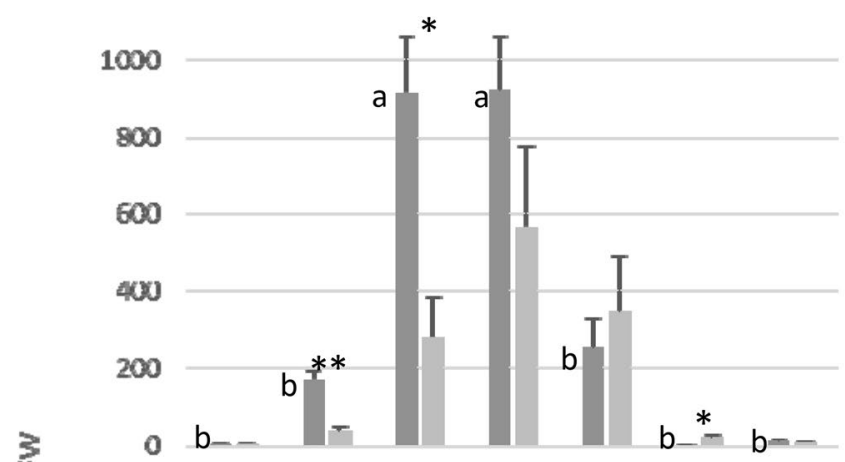

C

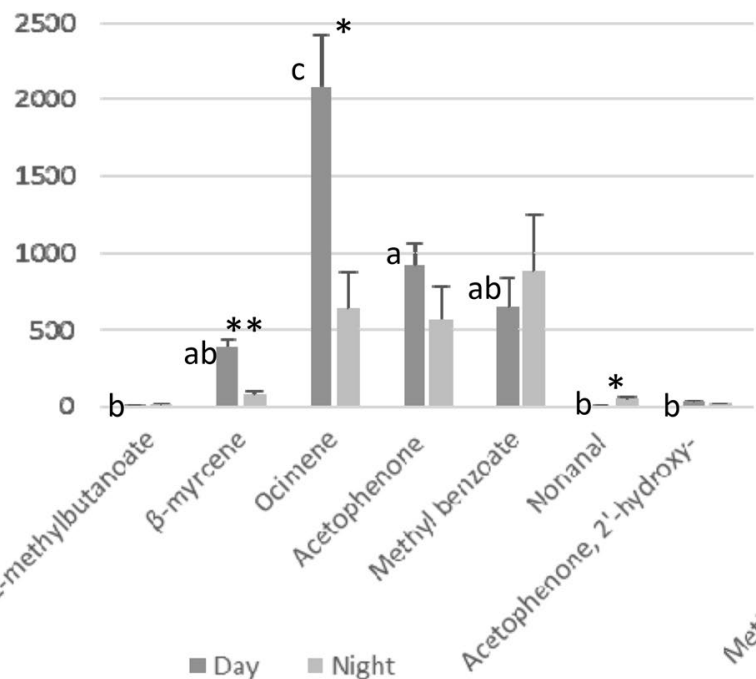

b

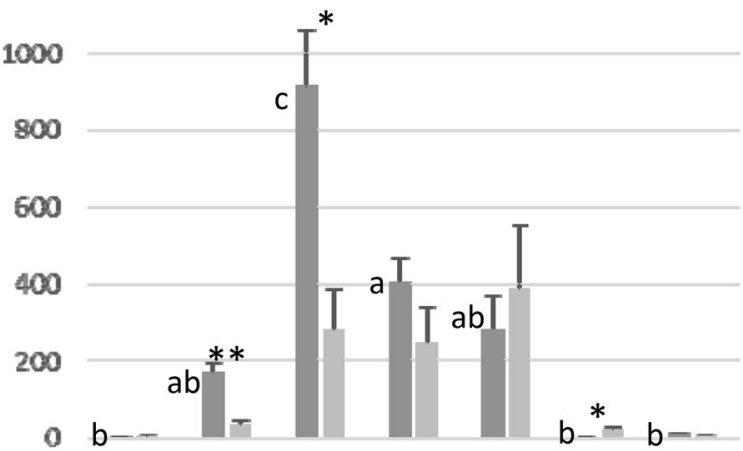

d

1000

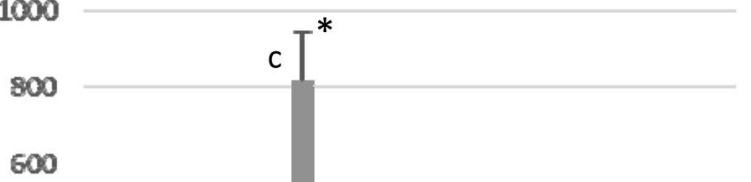

600
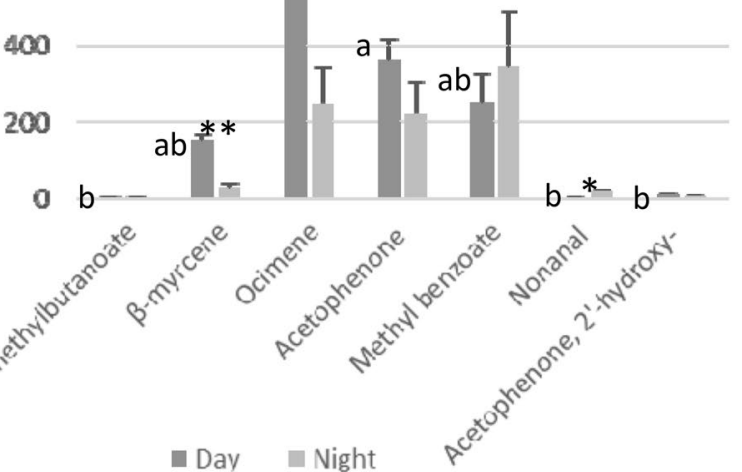

Fig. 5 Semi-quantification of VOC compounds emitted by A. majus flowers via external calibration curves carried out in the sampling system without flowers. a Application of the NearestRT calibration curve. b Application of single calibrator ocimene. c Application of single calibrator acetophenone. $\mathbf{d}$ Application of single calibrator methyl benzoate. Semi-quantifications were applied to raw data from day and night. Figures show the mean values in $\mu \mathrm{g} \mathrm{gFW}{ }^{-1}$ of three samples for each compound and error bars indicate the standard error. Different letters indicate statistical differences between compounds during the day. Asterisks indicate statistical differences of individual compound between day and night 
differences in VOC semi-quantification during a collection period of $12 \mathrm{~h}$ (day) (Fig. 6, Additional file 1: Tables S1, S2 and S3). Our results indicate that total quantities of compounds varied between the different approaches. For instance, ocimene emission during the day ranged from 93 to $132 \mu \mathrm{gFW}^{-1}$ depending on the calibration system (Fig. 6a, b). On the other hand, the variance and the statistical significances between compounds were maintained (Fig. 5a-d) as between ocimene and acetophenone with $p$ value of 0.00016 in case of the NearestRT and 0.0017 in case of the single calibrators (Tukey's test). When analysing the differences in VOC profiles between day and night, statistical significant patterns were maintained among calibrator approaches with ANOVA $p$ value for $\beta$-myrcene, ocimene and nonanal (Fig. 6, Additional file 1: Tables S4 and S6) of 0.0057, 0.024 and 0.017, respectively.

Our main conclusion regarding external calibration curves is that using a single calibrator provides identical statistical results irrespective of the compound or external calibrator chosen. In contrast, using the NearestRT, may be subject to changes depending on selected compounds.

\section{Method 3. Peak area per gram of FW}

An alternative method of reporting the relative abundance of compounds is expressing the total integrated area of each compound divided by the FW of the sample

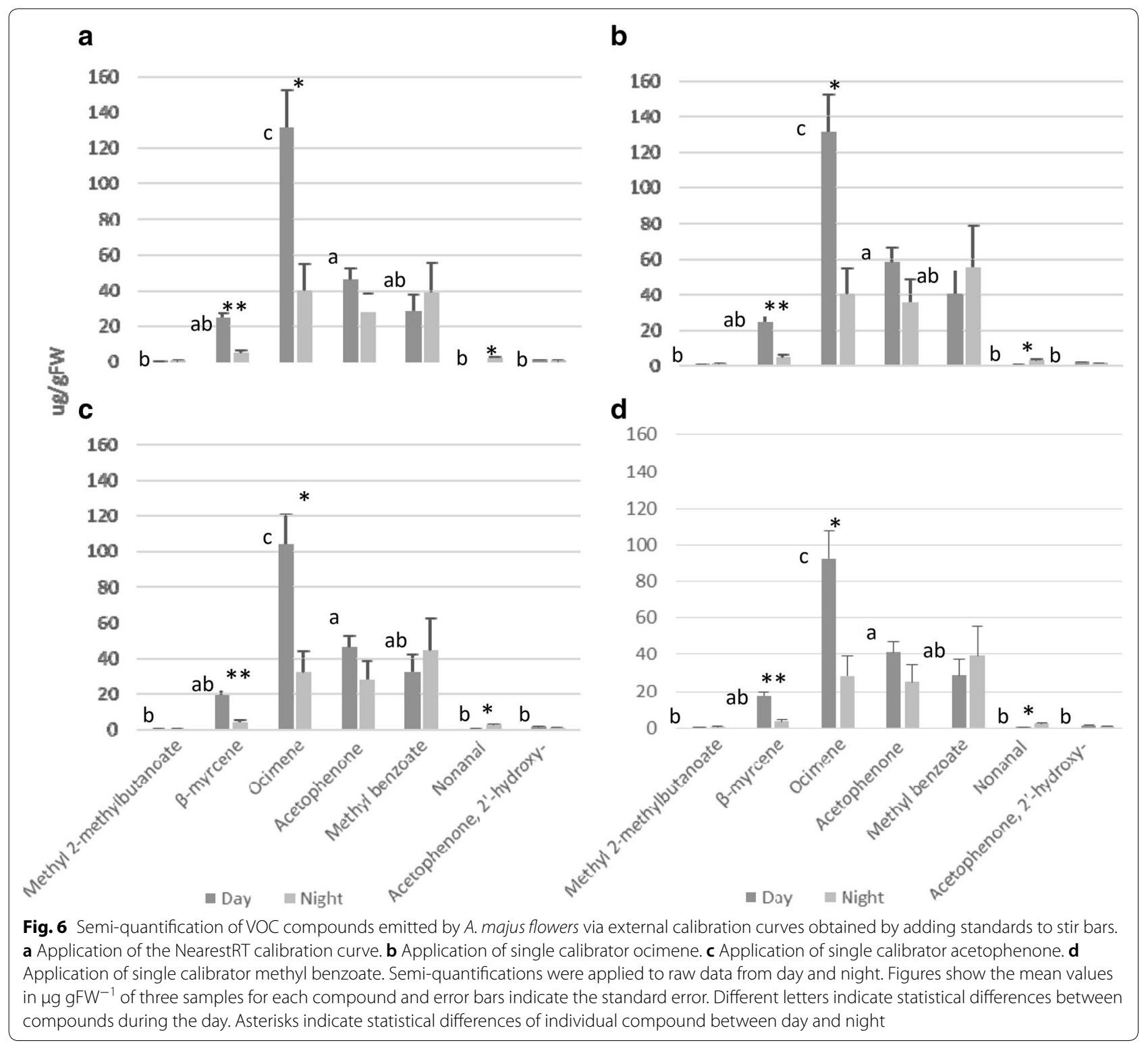


(Fig. 7a). We evaluated the statistical difference pattern among the relative amounts of compounds of the daylight profile and did not find differences compared to the previously presented methods. For instance, the difference in emission between ocimene and acetophenone was significant with a Tukey's $p$ value of 0.0017 , identical to the value obtained by single calibrators (Additional file 1: Tables S1, S2 and S3). Similarly, when analysing the emission of each compound during day and night, statistical significances were identical to those found for the two semi-quantification approaches based on calibration curves. ANOVA $p$ value for the differences in emission of $\beta$-myrcene, ocimene and nonanal during day and night were: $0.0057,0.024$ and 0.017 , respectively (Additional file 1: Tables S4 and S7).

\section{Method 4. Normalized peak area per gram of FW}

Normalizing gas-chromatographic data is understood as a way of decreasing the experimental error. For this normalization procedure, it is necessary to add a certain quantity of an internal standard not emitted by the sample.

Concerning the scent profiles emitted during the day, statistical results varied slightly compared to the methods applying the total integrated peak areas (see above). According to Tukey's test, acetophenone and ocimene emission were not statistically different $(P 0.056)$ (Fig. 7b, Additional file 1: Tables S1, S2 and S3). Likewise, comparative analysis of the emission between day and night resulted in a different statistical result compared to the previously described semi-quantitative approaches. In this case, the emission of $\beta$-myrcene and ocimene were significantly different $(P 0.0022$ and 0.0092$)$, but nonanal was not (P 0.072) (Fig. 7b, Additional file 1: Tables S4 and S7).

\section{Method 5. Semi-quantification based on internal standard abundance}

A quite extended method of semi-quantifying the emission of compounds is to extrapolate the integrated area of the added internal standard to the integrated area of any compound in the chromatogram.

When applying this method, mean quantities of every compound in the scent profile increased considerably compared to the semi-quantitative methods based on calibration curves. Regarding the statistical difference pattern among scent compounds emitted during the day as well as between day and night, results were identical to the normalized peak area method. During the day, a statistical difference between acetophenone and ocimene emission was lacking (Tukey $p$ value 0.056), (Fig. 7c, Additional file 1: Tables S1, S2 and S3). Similarly between day and night, the emission of $\beta$-myrcene and ocimene
$(P 0.0022$ and 0.0092$)$ was statistically significant, but not of nonanal ( $P$ 0.072) (Fig. 7c, Additional file 1: Tables S4 and S7).

\section{Method 6. Semi-quantification based on the nearest $n$-alkane} Following the key principle that similar compounds elute at similar retention times, we used $n$-alkanes to semiquantify our raw data. The nearest in retention time $n$-alkane (NearestRT alkane) has been used to semiquantify the compounds of interest. As an example, $\beta$-myrcene and ocimene (RT 5.57 and $6.615 \mathrm{~min}$, respectively) have been semi-quantitated by using decane (RT $5.82 \mathrm{~min}$ ) abundance (Table 3 ).

The analysis of the scent profile during the day (Fig. $7 \mathrm{~d}$, Additional file 1: Tables S1, S2 and S3) indicates that quantities of compounds varied largely when compared to the rest of approaches studied. Regarding the statistical difference pattern among compounds, these differences were similar to those obtained in semi-quantifications based on the methods using total peak areas (Fig. 7d), with a statistical difference between acetophenone and ocimene of $p$ value 0.025 (Tukey). Similarly, differences between day and night emission of $\beta$-myrcene, ocimene and nonanal were statistically significant (ANOVA $p$ value $0.0058,0.024$ and 0.018 , respectively) as already observed for the methods based on total peak areas (Fig. 7d, Additional file 1: Tables S4 and S7).

\section{Method 7. Percentage analysis}

A convenient way to show the relative abundance of VOCs within a scent profile is to express the data in percentages. We found that the statistical significance pattern among the compounds emitted during the day was similar to the NearestRT $n$-alkane method as well as those based on total peak area. We found a statistical difference between acetophenone and ocimene of Tukey's $p$ value 0.00062 (Fig. 7e, Additional file 1: Tables S1, S2 and S3). Concerning statistical differences between day and night, $\beta$-myrcene and nonanal showed significant difference whereas ocimene did not. ANOVA $p$ value for $\beta$-myrcene, ocimene and nonanal were: $0.035,0.132$ and 0.0043, respectively (Fig. 7e, Additional file 1: Tables S4 and 57 ).

\section{Discussion}

Most studies on VOCs emission concentrate on one to several compounds emitted by a set of samples [33-36], whereas fewer studies focus on entire scent profiles [8, 37-39]. The reason lies in the complexity of this type of analyses. Firstly, it requires the selection of an appropriate chromatographic method which allows to detect all emitted VOCs $[18,40]$. Secondly, many variables influence the quantity of VOCs released from the samples, 
a

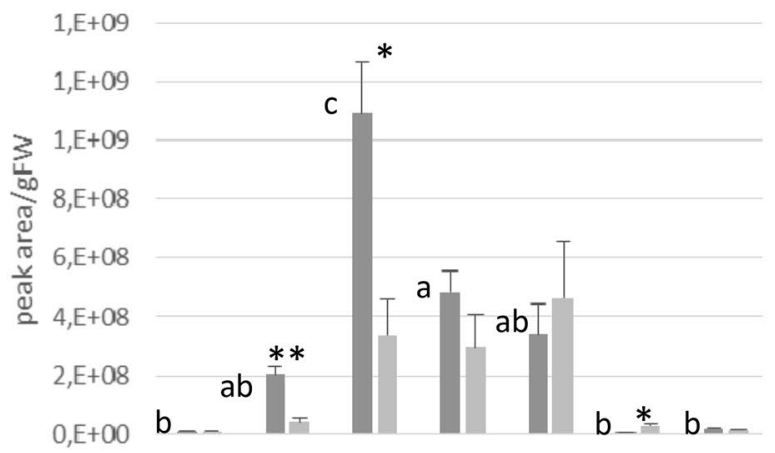

C

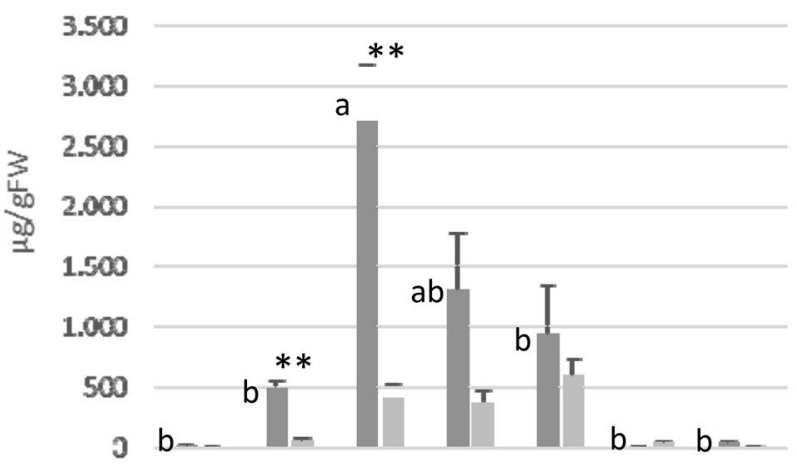

b

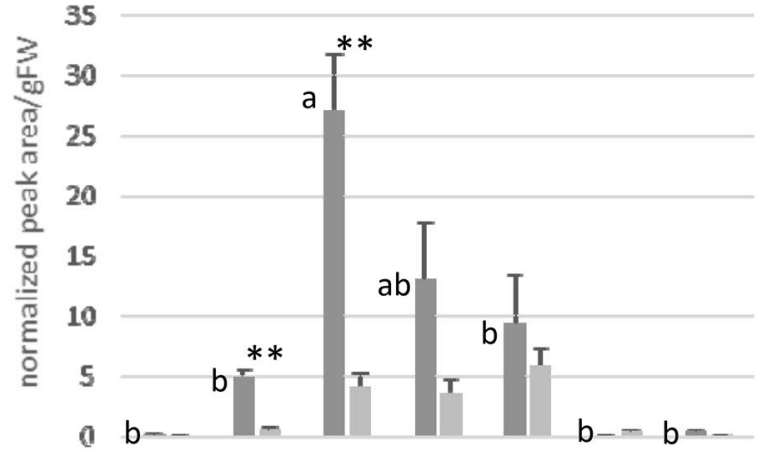

d

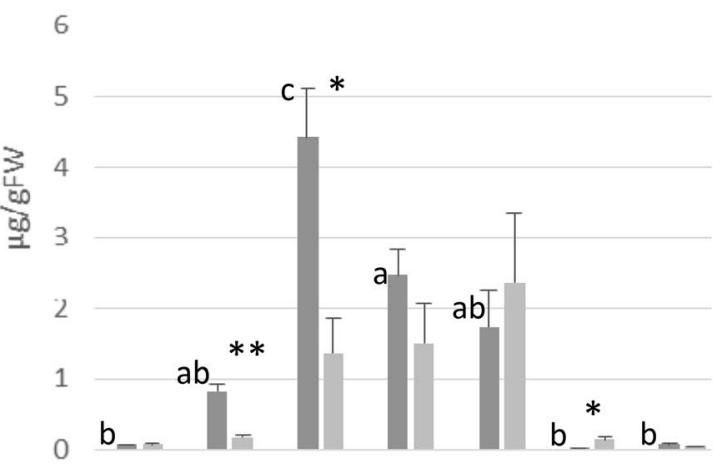

e
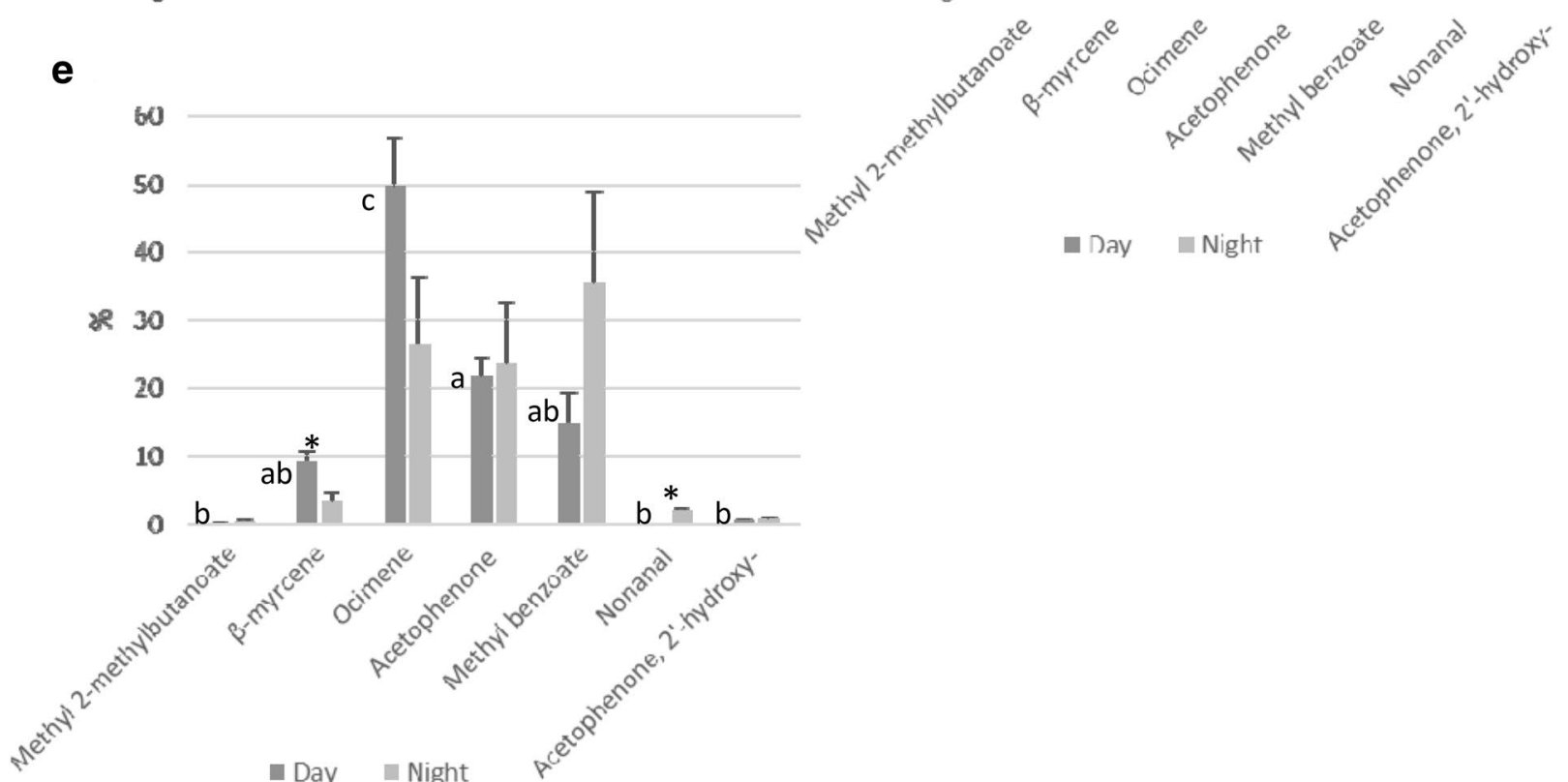

Fig. 7 Semi-quantifications of A. majus flowers profiles by using different methodologies based on: a total integrated peak area $\mathbf{b}$ normalized area, c single internal standard peak (1-phenylethanol), d NearestRT $n$-alkane abundance and e percentage abundance. Semi-quantifications were applied to raw data from day and night. Figures show the mean values of three samples for each compound and error bars indicate the standard error. Different letters indicate statistical differences between compounds during the day. Asterisks indicate statistical differences of individual compound between day and night 
such as light, temperature [37], physiological status of tissues [34] and even air pollution [41], leading to a high variability in the collected data [16]. Many investigators therefore concentrate on a few major compounds, which are constitutively emitted by their research objects, rather than dealing with minor compounds that may or may not be found due to reasons such as natural variability, VOC contamination or VOC emission in a circadian fashion [42]. On the other hand, studying the entire scent profile may give insight in very complex phenomena such as interactions between plants and pollinators $[40,43,44]$, volatile perception related to disease detection [7, 45-47], or pheromone signalling [48, 49]. Aromas are phenotypic traits that identify species as a result of evolutionary selection. Establishing which compounds and in which proportion contribute to scent profiles, is a determinant issue for characterizing species as well as for evaluating their effects over different taxa $[5,8,40,50]$.

\section{Sampling time and stir bars for HSSE}

The use of stir bars in HSSE analysis requires an atmosphere in equilibrium, sealed and isolated. PDMS coated stir bars preferably adsorb non-polar compounds. VOCs with different volatility will therefore be adsorbed differentially according to their chemical features [22, 51]. As shown in this work, the number of compounds identified is directly related to the time samples are exposed to the stir bars. This has important implications as VOCs emissions are under circadian regulation in many plants including Antirrhinum and Petunia [11, 32]. As sampling time plays a key role in the detection of rhythms, and sampling time of $4 \mathrm{~h}$ is the minimum required [25], our results indicate that increasing the sampling density will necessarily result in fewer minor VOCs identified.

Additionally, stir bars in headspace show a very high relative standard deviation [52]. Variability using stir bars results from two factors: changes in temperature and the matrix effect. The matrix effect is caused by the equilibrium conditions between matrix/headspace and the headspace/PDMS of the stir bar [52, 53]. In our study, temperature was under strict control and its effects on variability can be excluded. However, the matrix effect is difficult to control when complex matrices are used, such as plant tissues or organs.

\section{Normalized area vs total peak area}

Semi-quantification of compounds using normalized peak area is based on the usage of a specific amount of an internal standard. However, the standard may have chemical characteristics different to the compounds emitted by the sample and therefore may be adsorbed differently by the stir bar. This may cause miscalculations of quantities of VOCs emitted by samples. The use of dual-phase stir bars may improve detection of volatiles, because they more effectively recover polar analytes [54]. However, some drawbacks have been reported [44] and the degree of noise background introduced by these stir bars impedes the identification of minor VOCs.

\section{Comparison of NearestRT approaches}

Based on the key principle that chemically similar compounds elute at similar retention times, we used calibrators of compounds commonly found in the scent profile of $A$. majus as well as $n$-alkanes, which elute at similar retention times as the sample's compounds, for semiquantification. Both VOC quantities and proportions varied among the different NearestRT approaches, independent of whether calibrators were added to the headspace or as liquid to stir bars. To our knowledge, this is the first time that $n$-alkanes have been reported for semiquantifying VOCs as external calibrators. While the NearestRT approach has been applied in combination with internal standards $[15,21]$, its usage with external calibrators is not documented. We show that the NearestRT approaches presented here are equally valuable for scent profiling.

\section{Advantages and disadvantages of the studied methodologies}

We compared the effect of semi-quantification methods within scent profiles (day time samples) and between scent profiles (day and night time samples). The volatile proportions obtained by different semi-quantification methods, both on intra-sample and inter-sample data, even so not being identical clearly showed a similar trend. These small proportional discrepancies caused, in some cases, statistical variations. Nevertheless we consider that these small variations do not compromise any of the methods studied.

As shown in this work, several valid approaches exist for analysing GC-MS data using HSSE and TICs in terms of semi-quantification. All these procedures provide general, yet accurate, information about profile features. Nevertheless, each of the methodologies analysed here beholds specific advantages and disadvantages related to accuracy, experimental variability, acceptance and retrieved quantities (Table 4).

Regarding accuracy, the use of the NearestRT approach (methods 1B, 2 and 6) could be considered more appropriate than the single calibrator approach (methods $1 \mathrm{~B}$ and 2) and internal standard abundance (method 5), because chemically more similar compounds are used.

Concerning experimental variability, the outcome of external calibration curves in headspace is affected by the experimental conditions, like sampling time or volume in the headspace container, and need to be adapted to those 
Table 4 Overview of advantages and disadvantages of the semi-quantifying approaches

\begin{tabular}{|c|c|}
\hline Advantages & Disadvantages \\
\hline \multicolumn{2}{|c|}{ Method 1B. $\left({ }^{*}\right)$ External calibration curves obtained by adding standards to the sampling system } \\
\hline $\begin{array}{l}\text { High accuracy due to identical sampling conditions between external } \\
\text { calibrators and samples }\end{array}$ & $\begin{array}{l}\text { Calibration curves are valid only for the specific sampling conditions (i.e. } \\
\text { time or headspace volume) }\end{array}$ \\
\hline \multicolumn{2}{|c|}{ Method 2. $\left(^{*}\right)$ External calibration curves obtained by adding standards to stir bars } \\
\hline Calibration curves are valid independent of sampling conditions & $\begin{array}{l}\text { Lower accuracy due to different sampling conditions between external } \\
\text { calibrators and samples }\end{array}$ \\
\hline \multicolumn{2}{|l|}{ *NearestRT } \\
\hline $\begin{array}{l}\text { High accuracy due to the usage of chemically similar compounds for semi- } \\
\text { quantification }\end{array}$ & Several calibrators along the chromatogram need to be used \\
\hline \multicolumn{2}{|l|}{ *Single calibrator } \\
\hline $\begin{array}{l}\text { Statistical significance of the data is consistent, indicating that any calibrator } \\
\text { is valid }\end{array}$ & $\begin{array}{l}\text { A certain level of inaccuracy may result from a lack of chemical similarity } \\
\text { between calibrator and sample VOCs }\end{array}$ \\
\hline \multicolumn{2}{|l|}{ Method 3. Peak area/g fresh weight } \\
\hline It indicates the relative abundance among VOCs & There is no magnitude \\
\hline \multicolumn{2}{|l|}{ Method 4. Normalized peak area/g fresh weight } \\
\hline $\begin{array}{l}\text { Generally accepted as a precise mean to analyze relative abundance among } \\
\text { VOCs }\end{array}$ & $\begin{array}{l}\text { Bias due to differential stir bar adsorption between the internal standard } \\
\text { and certain kinds of VOCs } \\
\text { There is no magnitude }\end{array}$ \\
\hline \multicolumn{2}{|l|}{ Method 5. Single internal standard peak } \\
\hline Generally accepted as a precise mean for semi-quantification & $\begin{array}{l}\text { Bias due to differential stir bar adsorption between the internal standard } \\
\text { and certain kinds of VOCs }\end{array}$ \\
\hline \multicolumn{2}{|l|}{ Method 6. NearestRT n-alkane } \\
\hline $\begin{array}{l}\text { High accuracy due to the usage of chemically similar compounds for semi- } \\
\text { quantification }\end{array}$ & $\begin{array}{l}\text { A certain level of inaccuracy may result from a lack of chemical similarity } \\
\text { between calibrator and sample VOCs }\end{array}$ \\
\hline \multicolumn{2}{|l|}{ Method 7. Percentage analysis } \\
\hline $\begin{array}{l}\text { Generally accepted as a precise mean to analyze relative abundance among } \\
\text { VOCs }\end{array}$ & There is no magnitude \\
\hline
\end{tabular}

The asterisks indicate that NearestRT and single calibrator were used in method $1 \mathrm{~B}$ and method 2

used for VOC sampling. In contrast, this problematic does not occur when applying methods based on liquid addition directly to stir bars (method 2 and 6 ).

Quite popular methodologies are those based on internal standard abundance $[10,19,20,40]$ and percentages $[14,31,55,56]$, because they accurately reflect relative abundances. We show here that less common methods like total peak areas or normalized areas of compounds $[8,14]$ are valid alternatives for this purpose. However, none of these two approaches have a magnitude and understanding abundances is not straightforward. The single calibrator approach has been reported, but with some methodological differences [57] and no publications are available expressing results as total peak areas.gFW ${ }^{-1}$.

Regarding VOC quantities, the only informative methods are: external calibration curves from headspace (method 1B), external calibration curves from liquid addition to stir bars (method 2), semi-quantification based on a single internal standard peak $(\operatorname{method} 5)$ and semi-quantification based on the NearestRT $n$-alkane. However, quantities may vary depending on the methods and this difference should be taken into account especially when comparing results from different publications.

Despite all the divergences, all methods can be considered as reliable means of analysing scent profiles.

\section{Conclusions}

Two main conclusions can be drawn from this study. First, semi-quantification by standard addition is not a feasible method in sets of samples with a high biological variability, as in case of flowers. Secondly, any of the methodologies studied adequately reflects the relative proportion of VOCs when screening volatile metabolomes.

From our point of view and concerning the plant scent community, a general methodological consensus would be desirable in order to ease the comparison of data.

\section{Additional file}

Additional file 1. Statistical analysis of different semiquantitative methods. 


\section{Authors' contributions}

VRH and MJR conceived the ideas and designed methodology; $V R H, M J R, M E C$ and JW collected the data; VRH and MJR analysed the data; VRH, MJR, MEC and JW wrote the manuscript. All authors contributed critically to the drafts and gave final approval for publication. All authors read and approved the final manuscript.

\section{Author details}

${ }^{1}$ Instituto de Biotecnología Vegetal, Universidad Politécnica de Cartagena, Cartagena, Spain. ${ }^{2}$ Departamento de Ciencia y Tecnología Agraria, Universidad Politécnica de Cartagena, Cartagena, Spain. ${ }^{3}$ Servicio de Apoyo a la Investigación Tecnológica, Universidad Politécnica de Cartagena, Cartagena, Spain.

\section{Acknowledgements \\ Not applicable.}

\section{Competing interests}

The authors declare that they have no competing interests.

\section{Availability of data and materials}

Data deposited at the UPCT repository: http://repositorio.upct.es/.

\section{Consent for publication}

Not applicable.

\section{Ethics approval and consent to participate}

Not applicable.

\section{Funding}

This work was supported by Ministerio de Economía y Competitividad BFU2017-88300-C2-1R, Fundación Séneca 19398/PI/14 and by the Ministerio de Educación Cultura y Deporte (FPU13/03606) to VRH.

\section{Publisher's Note}

Springer Nature remains neutral with regard to jurisdictional claims in published maps and institutional affiliations.

Received: 19 April 2018 Accepted: 1 August 2018

Published online: 09 August 2018

\section{References}

1. Kesselmeier J, Staudt M. Biogenic volatile organic compounds (VOC): an overview on emission, physiology and ecology. J Atmos Chem. 1999;33:23-88

2. Schiestl FP. The evolution of floral scent and insect chemical communication. Ecol Lett. 2010;13:643-56.

3. Weiß BM, Marcillo A, Manser M, Holland R, Birkemeyer C, Widdig A. A noninvasive method for sampling the body odour of mammals. Methods Ecol Evol. 2017:9:420-9.

4. Pierik R, Ballaré CL, Dicke M. Ecology of plant volatiles: taking a plant community perspective. Plant Cell Environ. 2014;37:1845-53.

5. Knudsen JT, Eriksson R, Gershenzon J, Ståhl B. Diversity and distribution of floral scent. Bot Rev. 2006;72:1-120. https://doi.org/10.1663/00068101(2006)72[1:dadofs]2.0.co;2.

6. Isman MB. Botanical insecticides, deterrents, and repellents in modern agriculture and an increasingly regulated world. Ann Rev Entomol. 2006;51:45-66.

7. Groen SC, Jiang S, Murphy AM, Cunniffe NJ, Westwood JH, Davey MP, et al. Virus infection of plants alters pollinator preference: a payback for susceptible hosts? PLoS Pathog. 2016;12:e1005790.

8. Weiss J, Mühlemann JK, Ruiz-Hernández V, Dudareva N, Egea-Cortines M. Phenotypic space and variation of floral scent profiles during late flower development in Antirrhinum. Front Plant Sci. 2016;7:1903

9. Verdonk JC, Haring MA, van Tunen AJ, Schuurink RC. ODORANT1 regulates fragrance biosynthesis in petunia flowers. Plant Cell. 2005:17:1612-24.
10. Ashman TL, Bradburn M, Cole DH, Blaney BH, Raguso RA. The scent of a male: the role of floral volatiles in pollination of a gender dimorphic plant Ecology. 2005;86:2099-105. https://doi.org/10.1890/04-1161.

11. Hendel-Rahmanim K, Masci T, Vainstein A, Weiss D. Diurnal regulation of scent emission in rose flowers. Planta. 2007;226:1491-9. https://doi. org/10.1007/s00425-007-0582-3.

12. Callejón RM, González AG, Troncoso AM, Morales ML. Optimization and validation of headspace sorptive extraction for the analysis of volatile compounds in wine vinegars. J Chromatogr A. 2008;1204:93-103.

13. Ruiz-Hernández V, Hermans B, Weiss J, Egea-Cortines M. Genetic analysis of natural variation in antirrhinum scent profiles identifies benzoic acid carboxymethyl transferase as the major locus controlling methyl benzoate synthesis. Front Plant Sci. 2017;8:27. https://doi.org/10.3389/ fpls.2017.00027.

14. D'Agostino MF, Sanz J, Martínez-Castro I, Giuffrè AM, Sicari V, Soria AC. Statistical analysis for improving data precision in the SPME GC-MS analysis of blackberry (Rubus ulmifolius Schott) volatiles. Talanta. 2014:125:248-56

15. Raffo A, Masci M, Moneta E, Nicoli S, Sánchez del Pulgar J, Paoletti F. Characterization of volatiles and identification of odor-active compounds of rocket leaves. Food Chem. 2018;240:1161-70.

16. Roessner U, Wagner C, Kopka J, Trethewey RN, Willmitzer L. Simultaneous analysis of metabolites in potato tuber by gas chromatography-mass spectrometry. Plant J. 2000;23:131-42.

17. Khersonsky O, Roodveldt C, Tawfik DS. Enzyme promiscuity: evolutionary and mechanistic aspects. Curr Opin Chem Biol. 2006;10:498-508.

18. Marsili RT, Laskonis L. Evaluation of PDMS-based extraction techniques and GC-TOFMS for the analysis of off-flavor chemicals in beer. J Am Soc Brew Chem. 2006;65:129-37.

19. Ré DA, Raud B, Chan RL, Baldwin IT, Bonaventure G. RNAi-mediated silencing of the HD-Zip gene HD20 in Nicotiana attenuata affects benzyl acetone emission from corollas via ABA levels and the expression of metabolic genes. BMC Plant Biol. 2012;12:60.

20. Yue Y, Yu R, Fan Y. Transcriptome profiling provides new insights into the formation of floral scent in Hedychium coronarium. BMC Genom. 2015:16:470.

21. Albaigés J. Analytical techniques in environmental chemistry 2 : proceedings of the second international congress, Barcelona. Albaigés; 1981.

22. Lytovchenko A, Beleggia R, Schauer N, Isaacson T, Leuendorf JE, Hellmann $\mathrm{H}$, et al. Application of GC-MS for the detection of lipophilic compounds in diverse plant tissues. Plant Methods. 2009;5:4.

23. Nefzaoui A, Ben-Salem H. Opuntia forraje estratégico y herramienta eficiente para combatir la deertificación en la región wana.

24. Schwarz-Sommer Z, Gübitz T, Weiss J, Gómez-di-Marco P, Delgado-Benarroch $L$, Hudson A, et al. A molecular recombination map of Antirrhinum majus. BMC Plant Biol. 2010;10:275.

25. Hughes ME, Abruzzi KC, Allada R, Anafi R, Arpat AB, Asher G, et al. Guidelines for genome-scale analysis of biological rhythms. J Biol Rhythms. 2017:32:74873041772866.

26. Vcf Home [Internet]. 2018 [cited 2018 Mar 15]. http://www.vcf-online.nl/ VcfHome.cfm.

27. Adams RP. Identification of essential oil components by gas chromatography/mass spectroscopy. Carol Stream: Allured Publishing Corporation; 1995

28. Acree T, Arn H. Flavornet [Internet]. [cited 2018 Jan 23]. http://www.flavo rnet.org/f_kovats.html.

29. Lee SR, Macku C, Shibamoto T. Isolation and identification of headspace volatiles formed in heated butter. J Agric Food Chem. 1991;39:1972-5.

30. Zellner BA, Bicchi C, Dugo P, Rubiolo P, Dugo G, Mondello L. Linear retention indices in gas chromatographic analysis: a review. Flavour Fragr J. 2008;23:297-314.

31. Ruíz-Ramón F, Águila DJ, Egea-Cortines M, Weiss J. Optimization of fragrance extraction: daytime and flower age affect scent emission in simple and double narcissi. Ind Crops Prod. 2014;52:671-8. https://doi. org/10.1016/j.indcrop.2013.11.034

32. Kolosova N, Gorenstein N, Kish CM, Dudareva N. Regulation of circadian methyl benzoate emission in diurnally and nocturnally emitting plants. Plant Cell. 2001;13:2333-47.

33. Fernando LN, Grün IU. Headspace-SPME analysis of volatiles of the ridge gourd (Luffa acutangula) and bitter gourd (Momordica charantia) flowers. Flavour Fragr J. 2001;16:289-93. 
34. Kolosova N, Gorenstein N, Kish CM, Dudareva N. Regulation of circadian methyl benzoate emission in diurnally and nocturnally emitting plants. Plant Cell. 2001;13:2333-47. http://www.pubmedcentral.nih.gov/artic lerender.fcgi?artid=139162\&tool=pmcentrez\&rendertype=abstract. Accessed 14 Mar 2013.

35. Murfitt LM, Kolosova N, Mann CJ, Dudareva N. Purification and characterization of S-adenosyl-L-methionine:benzoic acid carboxyl methyltransferase, the enzyme responsible for biosynthesis of the volatile ester methyl benzoate in flowers of Antirrhinum majus. Arch Biochem Biophys. 2000;382:145-51. https://doi.org/10.1006/abbi.2000.2008.

36. Dudareva N, Martin D, Kish CM, Kolosova N, Gorenstein N, Fäldt J, et al. (E)-beta-ocimene and myrcene synthase genes of floral scent biosynthesis in snapdragon: function and expression of three terpene synthase genes of a new terpene synthase subfamily. Plant Cell. 2003;15:1227-41. http://www.pubmedcentral.nih.gov/articlerender.fcgi?artid=15372 8\&tool=pmcentrez\&rendertype=abstract. Accessed 24 Apr 2013.

37. Sagae M, Oyama-Okubo N, Ando T, Marchesi E, Nakayama M. Effect of temperature on the floral scent emission and endogenous volatile profile of Petunia axillaris. Biosci Biotechnol Biochem. 2008;72:110-5. http:// www.ncbi.nlm.nih.gov/pubmed/18175901. Accessed 7 Jun 2013.

38. Jirovetz L, Gonzalez JE, Silvera G, Nikiforov A, Woidich A. Volatile constituents of Peristeria elata (Orchidaceae). J Essent Oil Res. 1992;4:435-8.

39. Báez D, Pino JA, Morales D. Floral scent composition in Hedychium coronarium J. Koenig analyzed by SPME. J Essent Oil Res. 2011;23:64-7.

40. Friberg M, Schwind C, Raguso RA, Thompson JN. Extreme divergence in floral scent among woodland star species (Lithophragma spp.) pollinated by floral parasites. Ann Bot. 2013;111:539-50.

41. MCFrederick QS, Kathilankal JC, Fuentes JD. Air pollution modifies floral scent trails. Atmos Environ. 2008:42:2336-48.

42. Fenske MP, Imaizumi T. Circadian rhythms in floral scent emission. Front Plant Sci. 2016;7:462. https://doi.org/10.3389/fpls.2016.00462.

43. Ceuppens B, Ameye M, Van Langenhove H, Roldan-Ruiz I, Smagghe G. Characterization of volatiles in strawberry varieties "Elsanta" and "Sonata" and their effect on bumblebee flower visiting. Arthropod Plant Interact. 2015;9:281-7

44. Kfoury N, Scott E, Orians C, Robbat A. Direct contact sorptive extraction: a robust method for sampling plant volatiles in the field. J Agric Food Chem. 2017;65:8501-9.

45. Cornu JN, Cancel-Tassin G, Ondet V, Girardet C, Cussenot O. Olfactory detection of prostate cancer by dogs sniffing urine: a step forward in early diagnosis. Eur Urol. 2011;59:197-201.
46. Strauch M, Lüdke A, Münch D, Laudes T, Giovanni Galizia C, Martinelli E, et al. More than apples and oranges-detecting cancer with a fruit fly's antenna. Sci Rep. 2014;4(SREP03576):1-9.

47. Fernando WGD, Ramarathnam R, Krishnamoorthy AS, Savchuk SC. Identification and use of potential bacterial organic antifungal volatiles in biocontrol. Soil Biol Biochem. 2005;37:955-64.

48. Voznessenskaya W. Influence of cat odor on reproductive behavior and physiology in the house mouse: (Mus Musculus). In: Mucignat-Caretta C, editor. Neurobiology of chemical communication. Boca Raton: CRC Press/ Taylor \& Francis; 2014.

49. Wyatt TD. Pheromones and animal behavior: chemical signals and signatures, 2nd ed. Cambridge University Press; 2014.

50. Kessler D, Diezel C, Clark DG, Colquhoun TA, Baldwin IT. Petunia flowers solve the defence/apparency dilemma of pollinator attraction by deploying complex floral blends. Ecol Lett. 2013;16:299-306.

51. Salem MA, Jüppner J, Bajdzienko K, Giavalisco P. Protocol: a fast, comprehensive and reproducible one-step extraction method for the rapid preparation of polar and semi-polar metabolites, lipids, proteins, starch and cell wall polymers from a single sample. Plant Methods. 2016;12:45.

52. Barba C, Thomas-Danguin T, Guichard E. Comparison of stir bar sorptive extraction in the liquid and vapour phases, solvent-assisted flavour evaporation and headspace solid-phase microextraction for the (non)-targeted analysis of volatiles in fruit juice. LWT Food Sci Technol. 2017:85:334-44.

53. Bicchi C, Cordero C, Liberto E, Sgorbini B, Rubiolo P. Headspace sampling of the volatile fraction of vegetable matrices. J Chromatogr A. 2008;1184:220-33.

54. Sgorbini B, Cagliero C, Cordero C, Liberto E, Rubiolo P, Ruosi MR, et al. New medium-to-high polarity twister coatings for liquid and vapour phase sorptive extraction of matrices of vegetable origin. J Chromatogr A. 2012:1265:39-45.

55. Fraternale D, Flamini G, Ricci D, Giomaro G. Flowers volatile profile of a rare red apple tree from Marche region (Italy). J Oleo Sci. 2014;63:1195-201.

56. Rehman SU, Latief R, Bhat KA, Khuroo MA, Shawl AS, Chandra S. Comparative analysis of the aroma chemicals of Melissa officinalis using hydrodistillation and HS-SPME techniques. Arab J Chem. 2017;10:S2485-90.

57. Rule GS, Rockwood AL. Improving quantitative precision and throughput by reducing calibrator use in liquid chromatography-tandem mass spectrometry. Anal Chim Acta. 2016;919:55-61.
Ready to submit your research? Choose BMC and benefit from:

- fast, convenient online submission

- thorough peer review by experienced researchers in your field

- rapid publication on acceptance

- support for research data, including large and complex data types

- gold Open Access which fosters wider collaboration and increased citations

- maximum visibility for your research: over $100 \mathrm{M}$ website views per year

At BMC, research is always in progress.

Learn more biomedcentral.com/submissions 